\title{
The metagenomic approach to characterization of the microbial community shift during the long-term cultivation of anammox-enriched granular sludge
}

\author{
Slawomir Ciesielski ${ }^{1} \cdot \mathrm{Krzysztof}$ Czerwionka $^{2} \cdot$ Dominika Sobotka $^{2} \cdot$ Tomasz Dulski $^{1} \cdot$ Jacek Makinia $^{2}$
}

Received: 15 July 2017 / Revised: 2 November 2017 / Accepted: 21 November 2017 / Published online: 11 December 2017

(C) The Author(s) 2017. This article is an open access publication

\begin{abstract}
A metagenomic approach was used to investigate how the microbial community composition changes when an anammox-based granular sludge reactor is seeded with nitritation-anammox biomass from a wastewater treatment plant. In the seed sample, the abundance of Candidatus Kuenenia stuttgartiensis was similar to Candidatus Jettenia caeni (12.63 vs. 11.68\%). This biomass was typical in terms of microbial nitrogen conversion; both ammonia (Nitrosomonas sp.) and nitrite (Nitrospira sp.) oxidizing bacteria were detected. In the lab-scale reactor, Candidatus Kuenenia stuttgartiensis and Candidatus Jettenia caeni bacteria were also present in equal proportions (18.57 vs. 20.89\%). On the contrary, Candidatus Nitrospira defluvii bacteria were highly abundant in this reactor, but no known ammonia-oxidizing bacteria were detected. In light of recent studies showing that Nitrospira sp. are capable of complete nitrification, the results presented here may well indicate that both stages of nitrification in the anammox-based granular sludge reactor were performed by this bacteria.
\end{abstract}

Keywords Anammox $\cdot$ Biotransformation $\cdot$ Deammonification $\cdot$ Metagenomics $\cdot$ Wastewater treatment

\section{Introduction}

The anaerobic ammonium oxidation (anammox) process is now a proved feasible alternative to the conventional nitrification-denitrification for nitrogen removal from anaerobic digester effluents and anaerobically treated industrial effluents. The anammox bacteria are capable of converting ammonium to nitrogen gas $\left(\mathrm{N}_{2}\right)$ with nitrite as the final electron acceptor in the absence of dissolved oxygen (DO). Moreover, anammox does not require any organic carbon source for

Communicated by: Communicated by: Agnieszka Szalewska-Palasz

Electronic supplementary material The online version of this article (https://doi.org/10.1007/s13353-017-0418-1) contains supplementary material, which is available to authorized users.

Slawomir Ciesielski

slawomir.ciesielski@uwm.edu.pl

1 Department of Environmental Biotechnology, University of Warmia and Mazury in Olsztyn, Sloneczna 45G, 10-917 Olsztyn, Poland

2 Faculty of Civil and Environmental Engineering, Gdansk University of Technology, Narutowicza 11/12, 80-233 Gdansk, Poland dissimilatory nitrogen reduction. In comparison with the conventional nitrification/denitrification process, anammox has the advantages of higher nitrogen removal rates, lower operational costs, and smaller bioreactor's volume.

The deammonification process combines anammox with nitritation for the complete removal of ammonium from high-strength ammonium wastewater (Langone et al. 2014). In that process, ammonium oxidizing bacteria (AOB) convert approximately half of the ammonium to nitrite under DO limited conditions, and then the formed nitrite and remaining ammonium are converted to $\mathrm{N}_{2}$ by anammox bacteria (Pynaert et al. 2003). When organic carbon is available, heterotrophic denitrifiers may also exist in the deammonification systems and convert the nitrate produced by anammox bacteria (Kumar and Lin 2010). Because the deammonification process is strongly influenced by such factors as temperature, DO concentration, alkalinity, solids retention time, and $\mathrm{pH}$ (Zhang et al. 2008), the composition of microorganisms responsible for that process may be more complex and variable in comparison with the "pure" anammox process.

Although anammox-based technology has been more and more frequently used (Hu et al. 2012), the practical use of this process is still recognized as difficult mainly due to the long 
start-up periods which could sometimes require over one year. Such long start-up periods result from very low growth rates and biomass yields of anammox bacteria (Gutwinski et al. 2016; Ma et al. 2016). Thus, it is important to prevent the washout of anammox bacteria from the system by various techniques, including granular sludge (Gonzalez-Gil et al. 2015).

In order to shorten the long start-up periods with the anommox-based technology, anammox reactors are often inoculated with active biomass in either granular or free suspended biomass (Ni et al. 2011). Although the process of anammox start-up and enrichment has been studied (Trigo et al. 2006; López et al. 2008; Costa et al. 2014) the seeding of anaerobic anammox reactor with biomass from a nitritation/ anammox process has not been fully described on the molecular level. In the present study, analysis of metagenomic data were used to investigate the seeding of a laboratory-scale sequencing batch reactor (SBR) with active $\mathrm{AOB} /$ anammox biomass. In order to compare the microbial communities in the seeding material and the anammox-enriched sludge in the studied SBR, 16S RNA data from next-generation sequencing (NGS) were used. In addition, the next-generation DNA sequencing was also used to compare the functional metagenomic profiles of these communities.

\section{Materials and methods}

\section{Reactor set-up and operation}

The biogranulation experiment was carried out in a sequencing batch reactor (SBR) with a working volume of $10 \mathrm{~L}$, equipped with a control system for the measurement of DO concentrations, temperature, and $\mathrm{pH}$. The SBR was operated in the cycles consisting of four phases: mixed filling (30 min), mixing and reaction (60-660 min), settling (20 min), and drawing (10 min). The whole cycle duration of one cycle varied between 2 and $12 \mathrm{~h}$, depending on the actual anammox activity. The reactor was fed with synthetic medium favoring the growth of anammox bacteria (Table 1). The temperature set point was maintained at $30{ }^{\circ} \mathrm{C}$ $\left( \pm 1{ }^{\circ} \mathrm{C}\right)$, whereas $\mathrm{pH}$ was automatically maintained between 7.5-7.8. The SBR was operated for 52 weeks to obtain the explicit granulation effect. The values of ammonium, nitrite, and nitrate concentration in the influent and effluent are given in Table 2. The hydraulic retention time (HRT) was reduced during the SBR operation from 12 days to $8 \mathrm{~h}$ (Table 2). Concentrations of the nitrogen forms $\left(\mathrm{NH}_{4}-\mathrm{N}, \mathrm{NO}_{2}-\mathrm{N}, \mathrm{NO}_{3}-\mathrm{N}\right)$ were determined spectrophotometrically with cuvette tests (Hach Lange $\mathrm{GmbH}$ ) using Xion 500 spectrophotometer (Dr Lange GmbH, Berlin, Germany), according to Standard Methods (APHA 2005).
Table 1 Composition of the artificial medium

\begin{tabular}{ll}
\hline Compounds & Concentration, $\mathrm{mg} \mathrm{L}^{-1}$ \\
\hline Feeding composition & \\
$\mathrm{NH}_{4}{ }^{-}-\mathrm{N}$ & $100-500$ \\
$\mathrm{NO}_{2}{ }^{-}-\mathrm{N}$ & $100-650$ \\
$\mathrm{KHCO}_{3}$ & 1.25 \\
$\mathrm{CaCl}_{2}$ & 1.41 \\
$\mathrm{KH}_{2} \mathrm{PO}_{4}$ & 50.0 \\
$\mathrm{MgSO}_{4}$ & 58.6 \\
$\mathrm{FeSO}_{4} \cdot 7 \mathrm{H}_{2} \mathrm{O}$ & 9.08 \\
$\mathrm{EDTA}$ & 6.25 \\
$\mathrm{Trace} \mathrm{solution}^{*}$ composition & \\
$\mathrm{EDTA}$ & 15.0 \\
$\mathrm{ZnSO}_{4} \cdot 7 \mathrm{H}_{2} \mathrm{O}$ & 0.43 \\
$\mathrm{CoCl}_{2} \cdot 6 \mathrm{H}_{2} \mathrm{O}$ & 0.24 \\
$\mathrm{MnCl}_{2} \cdot 4 \mathrm{H}_{2} \mathrm{O}$ & 0.99 \\
$\mathrm{CuSO}_{4} \cdot 5 \mathrm{H}_{2} \mathrm{O}$ & 0.25 \\
$\left(\mathrm{NH}_{4}\right)_{6} \mathrm{Mo}_{7} \mathrm{O}_{24} \cdot 4 \mathrm{H}_{2} \mathrm{O}$ & 0.22 \\
$\mathrm{NiCl}_{2} \cdot 6 \mathrm{H}_{2} \mathrm{O}$ & 0.20 \\
$\mathrm{NaSeO}_{4} \cdot 10 \mathrm{H}_{2} \mathrm{O}$ & 0.20 \\
$\mathrm{H}_{3} \mathrm{BO}_{3}$ & 0.014 \\
$\mathrm{NaWO}_{4} \cdot 2 \mathrm{H}_{2} \mathrm{O}$ & 0.05 \\
\hline * tracer solution was added in the amount of $1.25 \mathrm{ml} \mathrm{L}$
\end{tabular}

*- tracer solution was added in the amount of $1.25 \mathrm{ml} \mathrm{L}^{-1}$

\section{Seeding biomass}

The inoculum biomass, originated from a full-scale sidestream treatment (deammonification) system in a municipal wastewater treatment plant in Zurich (Switzerland). Before the experiment began, the biomass had been stored for 32 weeks at room temperature and enriched twice a week with a mixture of $\mathrm{NH}_{4} \mathrm{Cl}$ and $\mathrm{NaNO}_{2}$. Due to the long-term storage of biomass under the substrate-limited conditions, the initial activity

Table 2 Initial and final ammonium, nitrite, and nitrate concentrations and hydraulic retention times (HRT) in the analyzed time points

\begin{tabular}{|c|c|c|c|c|c|}
\hline Timepoint & 1st day & 9th week & 28th week & 44th week & 52nd week \\
\hline HRT (d) & 12 & 1 & 0.66 & 0.33 & 0.33 \\
\hline \multicolumn{6}{|c|}{ Initial concentrations* $(\mathrm{mg} \mathrm{N} / \mathrm{L})$} \\
\hline $\mathrm{NH}_{4}-\mathrm{N}$ & 22.8 & 33.7 & 88.3 & 46.6 & 75.5 \\
\hline $\mathrm{NO}_{2}-\mathrm{N}$ & 24.8 & 41.7 & 142.5 & 53.0 & 89.2 \\
\hline $\mathrm{NO}_{3}-\mathrm{N}$ & 64.1 & 45.8 & 79.3 & 95.6 & 121.1 \\
\hline \multicolumn{6}{|c|}{ Final concentrations* (mg N/L) } \\
\hline $\mathrm{NH}_{4}-\mathrm{N}$ & 23.1 & 1.79 & 42.7 & 16.0 & 10.1 \\
\hline $\mathrm{NO}_{2}-\mathrm{N}$ & 25.1 & 1.11 & 72.5 & 9.4 & 7.3 \\
\hline $\mathrm{NO}_{3}-\mathrm{N}$ & 64.8 & 54.1 & 78.6 & 86.6 & 123.1 \\
\hline
\end{tabular}

*- the initial and final concentrations refer to the beginning and end, respectively, of the reaction phase 
of anammox bacteria in the studied SBR was hardly detectable $\left(0.016 \mathrm{gN} \mathrm{gVSS}^{-1} \mathrm{~d}^{-1}\right)$.

\section{DNA extraction}

Genomic DNA was extracted from $0.2 \mathrm{~g}$ of semidry of nitritation-anammox biomass used as inoculum (AMX_2013) and (AMX_2015) granular sludge sample collected after 52 weeks of the SBR operation. DNA was purified using FastDNA Spin Kit for soil (MP Biomedicals, USA) as per the manufacturer's instructions. Qubit 2.0 Fluorometer (Invitrogen, USA) was used to obtain accurate DNA quantification. The purified DNA was suspended in $100 \mu \mathrm{L}$ of deionized, DNAase free water and stored at $-20{ }^{\circ} \mathrm{C}$.

\section{Library preparation and Illumina sequencing}

The composition of microbial communities was identified by sequencing amplicon libraries created on the base of DNA extracted from the inoculum (AMX_2013) and sample withdrawn after 51 weeks of the SBR operation (AMX_2015). For this purpose, the V3-V4 region of the 16S rRNA gene was amplified from the metagenome using Illumina recommended PCR primers. These primers were created by adding Illumina adapter overhang nucleotide sequences to the PCR primers given by Klindworth et al. (2013). Following the amplification, PCR products for each sample were purified using the Agencourt AMPure XP PCR purification system (BeckmanCoultier) and quantified using the Qubit Fluorometer (Invitrogen, Carlsbad, CA). For the whole metagenome analysis (samples AMX_2013B and AMX_2015B), libraries were prepared using Nextera ${ }^{\circledR}$ XT DNA Sample Preparation Kit (Illumina, San Diego, USA). In both approaches, the samples were dually indexed using Nextera ${ }^{\circledR}$ XT Index Kit and DNA was sequenced on an Illumina MiSeq instrument using $2 \times$ 250 paired-end mode. For the sequencing, Miseq reagent kit v3 (Illumina, San Diego, USA) was used. All the procedures followed the manufacturers' instructions.

\section{Bioinformatic analyses}

Both 16S rRNA amplicons and metagenomes sequencing were performed using the Illumina approach. The sequencing results were recorded as fastq files and uploaded to the Meta Genome Rapid Annotation Subsystems Technology (MGRAST) server for analysis (Meyer et al. 2008). Each file was subjected to quality control (QC), which included quality filtering (removing sequences with $\geq 5$ ambiguous base pairs) and length filtering (removing sequences with a length $\geq 2$ standard deviations from the mean). The automated pipeline provided by MG-RAST was also used to obtain taxonomic classification using the BLAT program referencing the SILVA database. All the identifications were made using a maximum e-value of $1 \mathrm{e}-5$, a minimum identity cutoff of $90 \%$, and a minimum alignment length of $50 \mathrm{bp}$. The functional profiling was conducted by gene annotation with SEED subsystems using a hierarchical classification at E-value cutoff of 10-5 and a minimum alignment length of 15 amino acids in MG-RAST. Visualization was carried out using KEGG mapper. Taxonomic and functional differences between metagenomes were analyzed using Statistical Analysis of Metagenomic Profiles (STAMP v. 2.1.3) (Parks and Beiko 2010). Statistically significant differences between metagenomes were identified by Fisher's exact test combined with the Newcombe-Wilson method for calculating confidence. The Illumina metagenomic datasets are available at MG-RAST. Sequences data of the 16S rRNA gene are deposited under accession numbers 4629229.3 (AMX_2013), 4629228.3 (AMX_2015), whereas shotgun sequencing data are available under numbers: 4647330.3 (AMX_2013B), 4647329.3 (AMX_2015B).

\section{Results}

\section{Reactor performance}

The anammox-enriched granular sludge was successfully formed during the long-term biogranulation experiment conducted for 51 weeks. A measurable consumption of ammonia and nitrite began to be observed in the SBR after a 2 week start-up period. Subsequently, the nitrogen load was increased by either reducing the HRT or increasing the nitrogen concentration in the synthetic feed. In the course of the biogranulation study, optimization of the operational parameters (temperature, $\mathrm{DO}, \mathrm{pH}$, and free ammonia (FA) concentration) was performed. In order to determine the impact of FA on the anammox process rate, the NLR supplied to the reactor was gradually increased during the study period from 0.1 to $8.0 \mathrm{kgN} \mathrm{m}^{-3} \mathrm{~d}^{-1}$. It was found that the applied NLRs higher than $3.5 \mathrm{kgN}$ $\mathrm{m}^{-3} \mathrm{~d}^{-1}$ significantly affected the activity of anammox bacteria, which resulted in the elevated effluent concentrations of nitrogen compounds (ammonia and nitrite), e.g., on week 28 (Table 2). The nitrogen (sum of ammonium and nitrite) removal efficiency in the SBR increased from $54 \%$ on week 2 to over $98 \%$ at the end of the study (Fig. 1). Except for the periods in which the inhibitory effect of high concentration of FA on the anammox process was investigated (three intentional anammox inhibition tests on days 192, 270, and 323), the nitrogen (sum of ammonium and nitrite) removal efficiency in the studied SBR remained stably above $90 \%$. The overall nitrogen removal rate (NRR) and specific anammox activity (SAA) reached the maximum value of $5.3 \mathrm{kgNm}^{-3} \mathrm{~d}^{-1}$ and 1.6 kgNkgVSS ${ }^{-1} \mathrm{~d}^{-1}$, respectively." 
Fig. 1 Influent and effluent nitrogen (sum of ammonia and nitrite) concentrations in the studied SBR and nitrogen removal efficiencies observed during the long-term biogranulation experiment

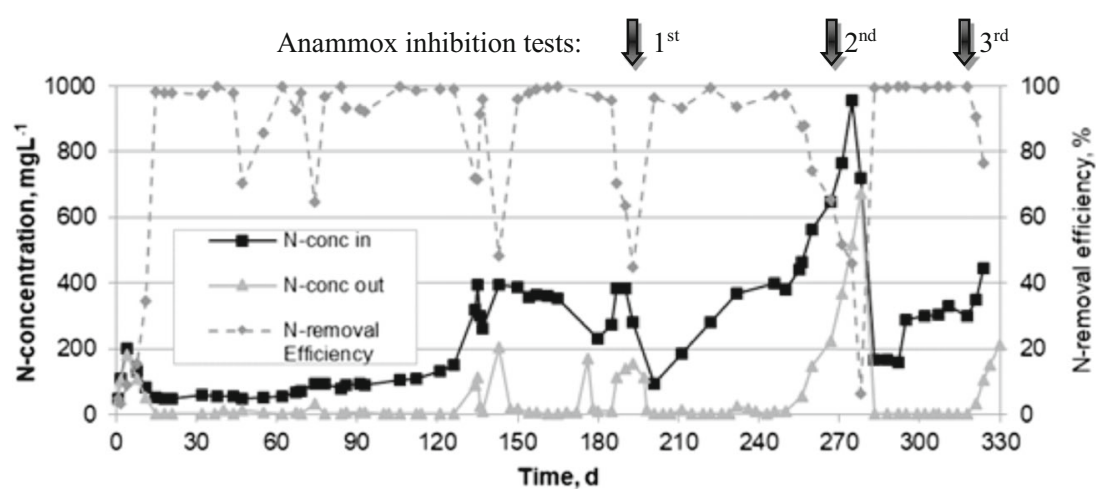

\section{Illumina sequencing}

In order to evaluate differences between microbial community composition in the seed sample (AMX_2013) and the enriched microbial community in the lab-scale reactor (AMX_2015), the data obtained by 16S rRNA gene sequencing were compared. The characteristics of the analyzed sequences are summarized in Table 3. Taxonomic affiliations were assigned to contigs with rRNA genes based on comparison with SILVA database. Alpha diversity was much higher for the seed sample (19.24) in comparison with the sample withdrawn from the reactor (11.65). Bacteria constituted the dominant domain in both seed sample (94.2\%) and enriched sample (94.3\%). At the phylum level, the most abundant bacteria found in the seed sample (AMX_2013) were Firmicutes, Planctomycetes, Proteobacteria, Actinobacteria, Chloroflexi and Acidobacteria. These bacteria accounted for 21.9, 21.0, $5.9,4.7,2.1$, and $2.0 \%$ of all the Bacteria reads, respectively. The most abundant phylum in sample AMX_2015 was Planctomycetes $(50.6 \%)$, followed by Proteobacteria (10.4\%), Actinobacteria (5.0\%), Bacteroidetes/Chlorobi (1.8\%), Firmicutes (1.6\%), and Chloroflexi (1.2\%).

At the family level, 154 and 137 families were found in AMX_2013 and AMX_2015 samples, respectively (Fig. S1). The proportions of the six major families are presented in Fig. 2. Contigs affiliated with Planctomycetaceae (12.63\%), unclassified Planctomycetales (11.68\%), Bacillaceae (6.53\%), Planococcaceae (3.22\%), Solibacteraceae (1.17\%), Herpetosiphonaceae $(1.17 \%)$ predominated in the seed sample (AMX_2013). In the second sample (AMX_2015), only members of Planctomycetaceae (18.57\%) and unclassified
Planctomycetales (20.89\%) were dominant. The statistically significant differences in the abundance of all genera between AMX_2013 and AMX_2015 were shown by the STAMP software (Fig. 3). In AMX_2013, which was characterized by a higher index of biodiversity than AMX_2015, anammox bacteria Candidatus Kuenenia stuttgartiensis (12.63\%) and Candidatus Jettenia caeni (11.68\%) predominated. In AMX_2015, the number of anammox bacteria increased to $18.57 \%$ ( $C a$. Kuenenia stuttgartiensis) and to $20.89 \%$ ( $C a$. Jettenia caeni). Contrary to anammox bacteria, nitrifying bacteria showed differences between samples. Ammoniaoxidizing Nitrosomonas europaea was detected only in the seed sample (0.23\%). Candidatus Nitrospira defluvii, contrary to Nitrosomonas europaea, was more abundant in the labscale reactor $(0.2 \%)$ than in the seed sample $(0.007 \%)$. The limited number of anammox bacteria in the seed sample was counterbalanced by numerous denitrifying genera such as Bacillus, Sporosarcina, Gordonibacter, and Clostridium.

A total of 264,731 and 178,371 protein-coding regions were predicted from the AMX_2013B and AMX_2015B metagenomes, respectively. For the AMX_2013B and AMX_2015B metagenomes, 122,383 (46.2\%) and 85,591 $(47.9 \%)$ predicted proteins were assigned and annotated, respectively. The remaining sequences had no significant similarity to any protein in the databases. Functional analyses were performed to compare metabolism profiles of the AMX_2013B and AMX_2015B metagenomes using SEED at level 1. The pathways showing significant differences between analyzed metagenomes are shown in Fig. 4. Genes whose numbers were significantly higher in the seed sample (AMX_2013B) were related to clustering-based systems, protein metabolism,
Table 3 Metagenomic sequence statistics obtained by Illumina approach. QF - quality filtering

\begin{tabular}{lllllc}
\hline Sample & Total reads & $\begin{array}{l}\text { Reads } \\
\text { (post QF) }\end{array}$ & $\begin{array}{l}\text { Mean sequence length } \\
\text { (post QF) bp }\end{array}$ & $\begin{array}{l}\text { Mean GC percent } \\
\text { (post QF) }\end{array}$ & $\alpha$ diversity \\
\hline AMX_2013 & 240,354 & 239,708 & $246 \pm 113$ & $56 \pm 3 \%$ & 19.24 \\
AMX_2015 & 324,519 & 324,031 & $292 \pm 62$ & $56 \pm 3 \%$ & 11.65 \\
AMX_2013_B & 460,435 & 431,009 & $220 \pm 50$ & $50 \pm 12 \%$ & - \\
AMX_2015_B & 363,763 & 333,500 & $225 \pm 48$ & $49 \pm 10 \%$ & - \\
\hline
\end{tabular}


Fig. 2 Family level affiliations assigned to contigs with $16 \mathrm{~S}$ rRNA genes in analyzed samples. Only orders with abundance higher than $1.0 \%$ are given

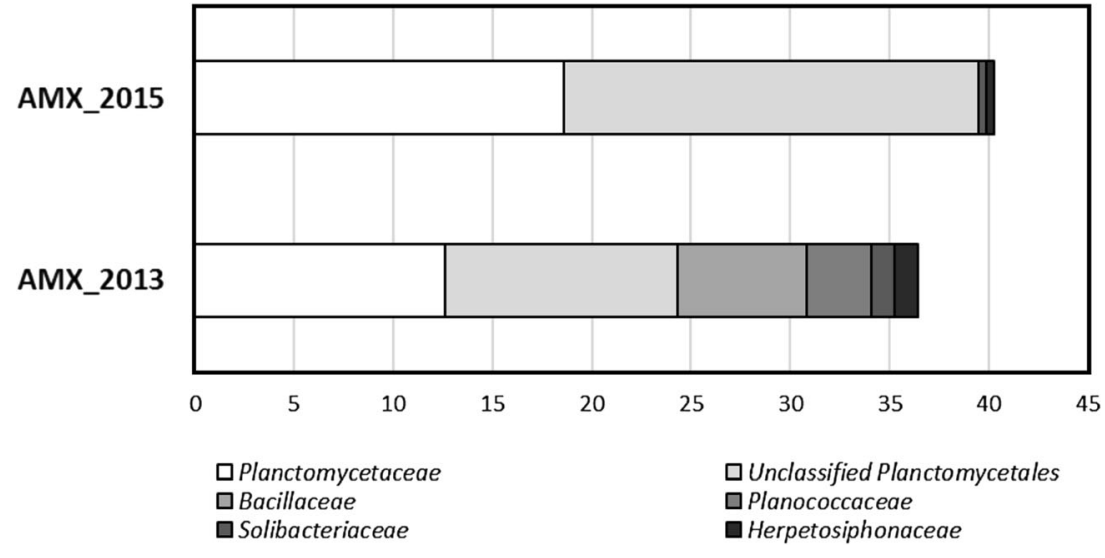

movable genetic factors (phages, prophages, transposable elements, plasmids), dormancy and sporulation, metabolism of amino acids and derivatives, regulation and cell signaling. Other genes with a significant overrepresentation in the AMX_2013B sample included those responsible for metabolism of fatty acids, lipids and isoprenoids, virulence, disease and defense, photosynthesis as well as for nucleosides and nucleotides metabolism. The AMX_2015B sample was found to have a significantly higher number of genes related to carbohydrate metabolism, respiration, metabolism of aromatic compounds and iron acquisition, membrane transport, sulfur metabolism and stress response. Moreover, in the sample from the reactor, genes related to cofactors, vitamins, prosthetic groups, pigments, and nitrogen metabolism were overrepresented.

Further analyses of the nitrogen metabolism (SEED level 3) revealed that in both analyzed metagenomes genes responsible for the ammonia assimilation, denitrification, nitric oxide synthase, nitrogen fixation, and nitrosative stress were present.

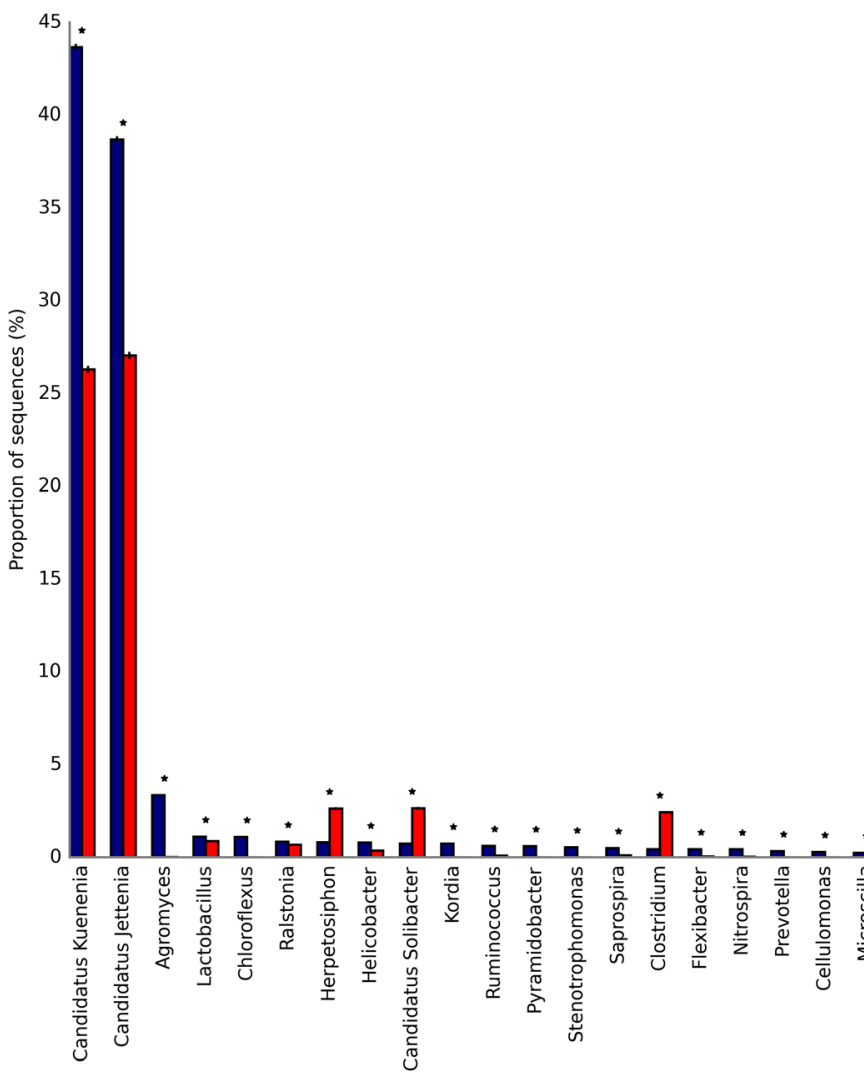

Fig. 3 Statistically significant differences between genera in seeding sample (AMX_2013) and sample from lab-scale reactor (AMX_2015). The graphic, obtained with the STAMP software, shows the differences between the proportions of sequences in each sample with a confidence interval of $95 \%$ 
Fig. 4 Statistically significant differences between bacterial metabolic profiles in seed sample (AMX_2013B) and sample from lab-scale reactor (AMX_2015B). The graphic obtained with the STAMP software, shows the differences between the proportions of sequences in each sample with a confidence interval of $95 \%$

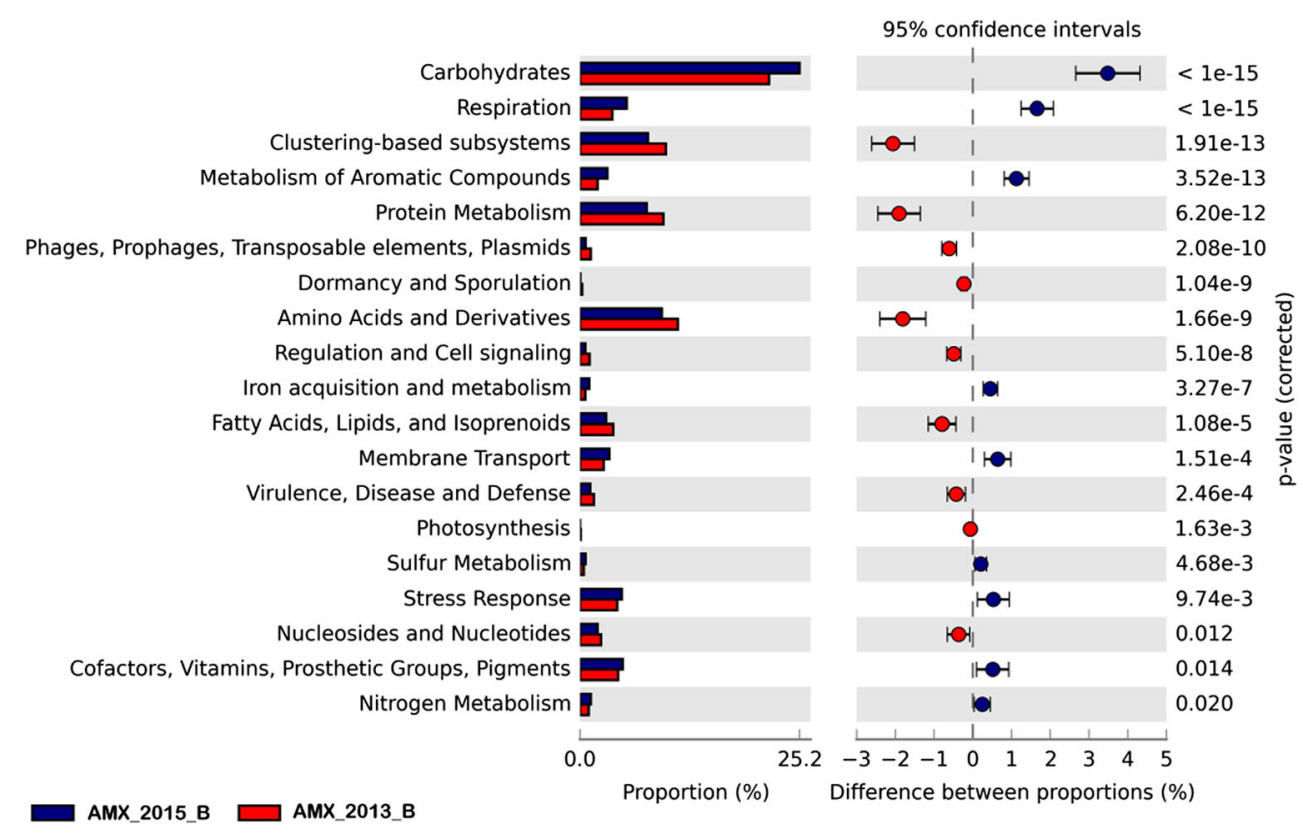

\section{Discussion}

However, the abundance of genes belonging to ammonia assimilation, nitrate and nitrite ammonification, and possible ammonia conversion cluster was significantly different in the studied metagenomes (Fig. 5). Only one gene, coding for coppercontaining nitrite reductase and representing the denitrification subsystem (NirK; EC 1.7.2.1), revealed a higher abundance in AMX_2013B. In the AMX_2015B metagenome, the abundance of six genes was significantly higher. Among them were three genes from the nitrate and nitrite ammonification subsystem, including respiratory nitrate reductase alpha and beta chain genes (NarG and NarH; EC 1.7.99.4) and the gene coding for nitrite reductase $\mathrm{NAD}(\mathrm{P}) \mathrm{H}$ large subunit (EC 1.7.1.4). The dissimilatory nitrite reductase subsystem was represented by the gene coding for nitrite reductase associated c-type cytochrome $(\mathrm{NirN})$. The denitrification subsystem was represented by genes responsible for nitrous-oxide reductase (EC 1.7.99.6) and nitrous oxide reductase maturation transmembrane (NosR). The functional composition of both metagenomes using the similarity to a non-redundant protein database against the KEGG metabolic pathway involved in the nitrogen conversion is shown in Fig. S2.
The results of this study demonstrated that the abundance of Planctomycetes members were similar in samples withdrawn from the nitritation-anammox WWTP (the seed biomass) and samples withdrawn after the long-term cultivation in the laboratory SBR. In both samples only $C a$. Kuenenia stuttgartiensis and $\mathrm{Ca}$. Jettenia caeni, formerly known as planctomycete KSU-1(Ali et al. 2015), were detected. The abundance of both bacteria was 1.47 ( $C a$. Kuenenia stuttgartiensis) and 1.78 (Ca. Jettenia caeni) times higher in enriched granular sludge. Ma et al. (2017) also showed dominance of $\mathrm{Ca}$. Kuenenia and $\mathrm{Ca}$. Jettenia in anoxic biofilm. However, in their work $\mathrm{Ca}$. Jettenia was much more abundant (17.83\%) than Ca. Kuenenia (2.62\%). Bae et al. (2007) examined granular anammox sludge and found that the second most common phylum was Planctomycetes (25\%), in which the most abundant clone was also $\mathrm{Ca}$. Jettenia caeni. Guo et al. (2016) also reported that Planctomycetes predominated in granular anammox sludge. Those authors found that the abundance of this phylum was $89.6 \%$ in a lab-scale reactor,

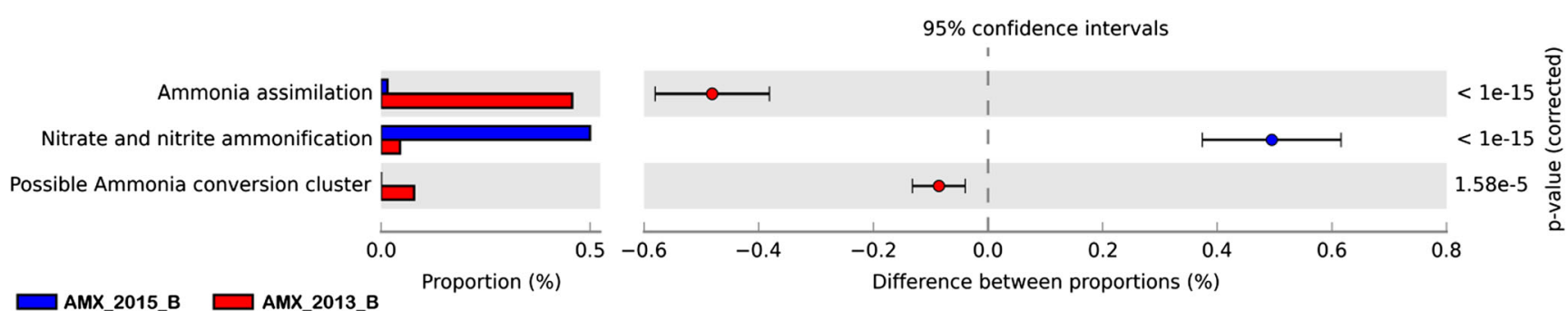

Fig. 5 Statistically significant differences in nitrogen metabolism derived from level 3 subsystem in seeding sample (AMX_2013B) and sample from lab-scale bioreactor (AMX_2015B). The graphic obtained with the
STAMP software, shows the differences between the proportions of sequences in each sample with a confidence interval of $95 \%$ 
however the predominant taxon was Candidatus Kuenenia. Chen et al. (2012) also showed that $C a$. Kuenenia stuttgartiensis were the dominant anammox bacteria in granular sludge at high substrate concentrations. Moreover, Gonzalez-Gil et al. (2015) found that most of the bacteria in a full scale reactor belonged to $\mathrm{Ca}$. Kuenenia stuttgartiensis as shown by MG-RAST metagenomic analysis. Although, many papers deal with anammox bacteria, our study showed for the first time, the equal abundance of $C a$. Kuenenia and $C a$. Jettenia. Bae et al. (2007) reported that granular sludge comprised, in addition to Planctomycetes, bacteria from Proteobacteria (47\%), Chloroflexi (18\%), Chlorobi (8\%), and Acidobacteria (2\%) phyla. The structure of the microbial community in the study of Bae et al. (2007) was similar to the present study (AMX_2015 sample), even though the proportions of the specific phyli are different.

The results of the present study showed that $C a$. Kuenenia stuttgartiensis and $\mathrm{Ca}$. Jettenia caeni were present in similar numbers in the anammox granular sludge. One of the differences between these two bacteria is their nitrite reductase genes. $\mathrm{Ca}$. Kuenenia stuttgartiensis possess a gene for a cytochrome $c d 1$-type nitrite reductase (nirS), whereas $C a$. Jettenia caeni have a copper nitrite reductase gene (nirK) (Hu et al. 2012). The NirK gene has been previously detected in denitrifiers but not in anammox bacteria other than KSU-1 (Hira et al. 2012). The presence of nirK in the experimental anammox reactor suggests that this nitrite reductase could play a major role in the granular anammox process.

In contrast to the typical anammox biomass, nitritationanammox (deammonification) biomass is characterized by a high diversity of denitrifiers, showing the importance of denitrification in nitritation-anammox systems (Langone et al. 2014). In studied metagenomes (AMX_2013B and AMX_2015B), both forms of nitrite reductase, nirS and nirK, were present. Although the abundance of the nirS gene did not differ significantly between samples, nirK gene number was significantly higher in the nitritation-anammox biomass. This difference may be due to the fact that numerous denitrifiers were present in the seed sample, including Bacillus, Ralstonia, Sporosarcina, Gordonibacter, and Clostridium, although it is also possible that other bacteria were carrying the $\operatorname{nirK}$ gene because it is easily spread through lateral gene transfer (Heylen et al. 2006).

Until now, the full nitrification had only been described as occurring as the result of cooperation between $\mathrm{AOB}$ and nitrite oxdizing bacteria (NOB). However, van Kessel et al. (2015) and Daims et al. (2015) have shown that Nitrospira $\mathrm{sp}$. is able not only to oxidize nitrite to nitrate but also to perform the first stage of nitrification, oxidizing ammonia to nitrite. In this new paradigm, Nitrospira sp. is not competing with anammox bacteria, but actually helping anammox bacteria by providing them with extra nitrite.
In the light of these findings, the results of the present study may indicate that, nitrification in the experimental reactor was implicitly performed by Candidatus Nitrospira defluvii belonging to Nitrospira sublineage I (Lücker et al. 2010). The evidence for these findings is that only a few $(0.003 \%)$ AOB from Nitrosomonas genus were detected in the granular sludge sample, whereas the number of bacteria belonging to Nitrosomonas species was relatively high in the seed sample $(0.37 \%)$. The abundance of $C a$. Nitrospira defluvii was significantly higher in the experimental reactor in comparison with the seed sample. It is likely that, in this reactor, $C a$. Nitrospira defluvii replaced AOB, because it is more flexible and able to survive periods of oxygen depletion (Koch et al. 2015). A similar finding was done by Bagchi et al. (2016), who noted the presence of a Nitrospira-like organism with a metabolic potential for complete ammonia oxidation to nitrate in a sidestream deammonification pilot reactor. The metagenomics analysis performed by the authors revealed, based on the identified ferredoxin nitrite reductase, that discovered Nitrospira was also taxonomically affiliated with I sublineage. The presence of a Nitrospira-like organism with the metabolic potential to perform the complete oxidation of ammonia to nitrate was also reported by Pinto et al. (2015). All these observations suggested, that comammox is more essential for ammonia transformation than previously thought.

Finally, the metagenomic analysis has provided interesting information about similarities in the functional traits. Focusing on the nitrogen conversion metabolic pathways, it was observed that, except for the nirK gene overrepresented in the seed sample, only a few genes were more abundant in the experimental reactor. Their high abundance may be related to the prevalent number of anammox bacteria in the sample from the experimental reactor. In general, metagenomic analysis gives an overview of the functional capabilities and differences between analyzed metagenomes. The most significant differences were observed for the reads related to carbohydrates, respiration, aromatic compounds and proteins metabolism, and various functions grouped in clusteringbased subsystems (Fig. 4). The metabolic profile obtained for experimental (AMX_2015B) was very similar to the results reported by Gonzalez-Gil et al. (2015) for granular anammox sludge (MG-RAST accession number 4544122). The sample analyzed by Gonzalez-Gil et al. (2015) was however withdrawn from a $70 \mathrm{~m}^{3}$ full-scale anammox reactor. This suggests that no matter the scale, it is possible to obtain similar metabolic pathways despite differences in the microbial composition.

To sum up, the present study demonstrated that an anaerobic granular anammox reactor was successfully started up using nitritation-anammox biomass. In spite of the fact that 
the sample was deposited for months, it was a good source of seeding material for the anammox process. The results showed that Ca. Kuenenia stuttgartiensis could coexist with $\mathrm{Ca}$. Jettenia caeni in nitritation-anammox biomass as well as in granular anammox biomass. The most interesting finding of this work refers to the possibility of complete nitrification by $\mathrm{Ca}$. Nitrospira defluvii in the experiental reactor. Based on the obtained results, it could be hypothesized that $C a$. Nitrospira defluvii were responsible for comammox in the reactor and provided the extra nitrite load for anammox bacteria.

Acknowledgements This work was supported by the National Science Centre (Poland) under project no. UMO-2011/01/B/ST8/07289.

Statement of author contributions S.C. conducted molecular analyses, computational work and drafted the manuscript. K.C. helped to conduct technological processes and chemical analyses. D. S. carried out the technological processes and conducted chemical analyses. T.D. helped to conduct molecular analyses. J.M. reviewed the final draft and supervised the experimental work. All authors contributed to writing the final manuscript. All authors read and approved the final manuscript.

\section{Compliance with ethical standards}

Conflict of interest All suthors declare that they have no conflict of interest.

Ethical approval This article does not contain any studies with human participants or animals performed by any of the authors.

Open Access This article is distributed under the terms of the Creative Commons Attribution 4.0 International License (http:// creativecommons.org/licenses/by/4.0/), which permits unrestricted use, distribution, and reproduction in any medium, provided you give appropriate credit to the original author(s) and the source, provide a link to the Creative Commons license, and indicate if changes were made.

\section{References}

Ali M, Oshiki M, Awata T et al (2015) Physiological characterization of anaerobic ammonium oxidizing bacterium "Candidatus Jettenia caeni.”. Environ Microbiol. https://doi.org/10.1111/1462-2920. 12674

APHA (2005) Standard methods for the examination of water and wastewater, 21th edn. American Public Health Association, Washington, DC

Bae H, Park K-S, Chung Y-C, Jung J-Y (2007) Occurence of KSU-1 type anammox bacteria and predominance of beta-proteobacteria in the anammox granular sludge. Proc Water Environ Fed 2007:30523066. https://doi.org/10.2175/193864707787973671

Bagchi S, Russel E, Sturm BSM (2016) Proceedings of the WEF/IWA Nutrient Removal and Recovery, Denver, CO

Chen T-T, Zheng P, Shen L-D et al (2012) Dispersal and control of anammox granular sludge at high substrate concentrations. Biotechnol Bioprocess Eng 17:1093-1102. https://oi.org/10.1007/ s12257-012-0086-2

Costa MCMS, Carvalho L, Leal CD et al (2014) Impact of inocula and operating conditions on the microbial community structure of two anammox reactors. Environ Technol 35:1811-1822. https://doi.org/ $10.1080 / 09593330.2014 .883432$
Daims H, Lebedeva EV, Pjevac P et al (2015) Complete nitrification by Nitrospira bacteria. Nature 528:504-509. https://doi.org/10.1038/ nature 16461

Gonzalez-Gil G, Sougrat R, Behzad AR et al (2015) Microbial community composition and ultrastructure of granules from a full-scale anammox reactor. Microb Ecol 70:118-131. https://doi.org/10. 1007/s00248-014-0546-7

Guo J, Peng Y, Fan L et al (2016) Metagenomic analysis of anammox communities in three different microbial aggregates. Environ Microbiol 18:2979-2993. https://doi.org/10.1111/1462-2920.13132

Gutwinski P, Cema G, Ziembinska-Buczynska A, Surmacz-Gorska J, Osadnik M (2016) Startup of the anammox process in a membrane bioreactor (AnMBR) from conventional activated sludge. Water Environ Res 88:2268-2274. https://doi.org/10.2175/ $106143016 X 14733681695960$

Heylen K, Gevers D, Vanparys B et al (2006) The incidence of nirS and nirK and their genetic heterogeneity in cultivated denitrifiers. Environ Microbiol 8:2012-2021. https://doi.org/10.1111/j.14622920.2006.01081.x

Hira D, Toh H, Migita CT et al (2012) Anammox organism KSU-1 expresses a NirK-type copper-containing nitrite reductase instead of a NirS-type with cytochrome cd1. FEBS Lett 586:1658-1663. https://doi.org/10.1016/j.febslet.2012.04.041

$\mathrm{Hu}$ Z, Speth DR, Francoijs K-J et al (2012) Metagenome analysis of a complex community reveals the metabolic blueprint of anammox bacterium Candidatus Jettenia asiatica. Front Microbiol 3:366. https://doi.org/10.3389/fmicb.2012.00366

Klindworth A, Pruesse E, Schweer T et al (2013) Evaluation of general $16 \mathrm{~S}$ ribosomal RNA gene PCR primers for classical and nextgeneration sequencing-based diversity studies. Nucleic Acids Res 41:e1. https://doi.org/10.1093/nar/gks808

Koch H, Lücker S, Albertsen M et al (2015) Expanded metabolic versatility of ubiquitous nitrite-oxidizing bacteria from the genus Nitrospira. Proc Natl Acad Sci U S A 112:11371-11376. https:// doi.org/10.1073/pnas. 1506533112

Kumar M, Lin J-G (2010) Co-existence of anammox and denitrification for simultaneous nitrogen and carbon removal-strategies and issues. J Hazard Mater 178:1-9. https://doi.org/10.1016/j.jhazmat. 2010.01.077

Langone M, Yan J, Haaijer SCM et al (2014) Coexistence of nitrifying, anammox and denitrifying bacteria in a sequencing batch reactor. Front Microbiol 5:28. https://doi.org/10.3389/fmicb.2014.00028

López H, Puig S, Ganigué R et al (2008) Start-up and enrichment of a granular anammox SBR to treat high nitrogen load wastewaters. J Chem Technol Biotechnol 83:233-241. https://doi.org/10.1002/jctb. 1796

Lücker S, Wagner M, Maixner F et al (2010) A Nitrospira metagenome illuminates the physiology and evolution of globally important nitrite-oxidizing bacteria. Proc Natl Acad Sci U S A 107:1347913484. https://doi.org/10.1073/pnas.1003860107

Ma B, Wang S, Cao S et al (2016) Biological nitrogen removal from sewage via anammox: recent advances. Bioresour Technol 200: 981-990. https://doi.org/10.1016/j.biortech.2015.10.074

Ma B, Qian W, Yuan C et al (2017) Achieving mainstream nitrogen removal through coupling anammox with denitratation. Environental Sci Technol 51:8405-8413. https://doi.org/10.1021/ acs.est.7b01866

Meyer F, Paarmann D, D'Souza M et al (2008) The metagenomics RAST server - a public resource for the automatic phylogenetic and functional analysis of metagenomes. BMC Bioinformatics 9:386. https:// doi.org/10.1186/1471-2105-9-386

Ni S-Q, Gao B-Y, Wang C-C et al (2011) Fast start-up, performance and microbial community in a pilot-scale anammox reactor seeded with exotic mature granules. Bioresour Technol 102:2448-2454. https:// doi.org/10.1016/j.biortech.2010.11.006 
Parks DH, Beiko RG (2010) Identifying biologically relevant differences between metagenomic communities. Bioinformatics 26:715-721. https://doi.org/10.1093/bioinformatics/btq041

Pinto AJ, Marcus DN, Ijaz UZ et al (2015) Metagenomic evidence for the presence of comammox Nitrospira-like bacteria in a drinking water system. mSphere 1(1).pii:e00054-15. https://doi.org/10.1128/ mSphere.00054-15

Pynaert K, Smets BF, Wyffels S et al (2003) Characterization of an autotrophic nitrogen-removing biofilm from a highly loaded lab-scale rotating biological contactor. Appl Environ Microbiol 69:36263635. https://doi.org/10.1128/aem.69.6.3626-3635.2003
Trigo C, Campos JL, Garrido JM, Méndez R (2006) Start-up of the anammox process in a membrane bioreactor. J Biotechnol 126: 475-487. https://doi.org/10.1016/j.jbiotec.2006.05.008

van Kessel MAHJ, Speth DR, Albertsen M et al (2015) Complete nitrification by a single microorganism. Nature 528:555-559. https:// doi.org/10.1038/nature16459

Zhang L, Zheng P, Tang C, Ren-cun J (2008) Anaerobic ammonium oxidation for treatment of ammonium-rich wastewaters. J Zhejiang Univ Sci B 9:416-426. https://doi.org/10.1631/jzus.B0710590 